\title{
$\mathrm{MIMO}$ 시스템에서 반복 복호 알고리즘 기반의 계층적 시공간 부호화 방식 연구
}

\author{
박태두 * + 정지원 \\ * 한국해양대학교 전파공학과 대학원, † 한국해양대학교 전파공학과 정교수
}

\section{A Study on layered Space Time Trellis codes for MIMO system based on Iterative Decoding Algorithm}

\author{
Tae-Doo Park* • † Ji-Won Jung \\ *, + Dongsam-dong, Yeongdo-Gu, Dept. of Radio Science Engineering, Korea Maritime University, Busan 606-791, Korea
}

\begin{abstract}
요 약 : 차세대 무선통신에서는 다양한 서비스, 높은 신뢰도와 함께 빠른 전송속도를 요구한다. 이러한 요구를 만족시키기 위해서 시공간 격자부호와 터보 부호기를 결합시키는 계층적 시공간 부호기를 사용하였다. 계층적 시공간 부호기에서는 내부 부호와 외부 부호의 두 부호를 연속적으로 연접 시키는 방식이다. 내부 부호로는 DVB-RCS NG 시스템에서 표준으로 제안된 터보 $\mathrm{Pi}$ 부호를 사용하고, 외부 부호로는 Blum에 의해 제안된 시공간 격자 부호를 사용한다. 또한 효율적으로 두 부호기를 연접시키기 위하여 인터리버 기법을 사용한다. 그리고 기존 의 복호 방법은 시공간 격자 부호와 터보 복호기 내부에서만 반복 복호를 하지만, 본 논문에서는 $\mathrm{BCJR}$ 복호기와 함께 전체 반복을 통하여 성능을 향상시키는 방안을 제시하고 시뮬레이션 하였다. 시뮬레이션 결과 본 논문에서 제시하는 효율적인 연접 방식을 이용하면 일반적인 연 접 방식에 비하여 약 $1.3 \sim 1.5 \mathrm{~dB}$ 의 성능이 향상되었다.
\end{abstract}

핵심용어 : $\mathrm{MIMO}$, 시공간 부호, 터보 부호, 인터리버

Abstract : The next-generation wireless communication requires fast transmission speeds with various services and high reliability. In order to satisfy these needs we study MIMO system used layered space time coded system (LST) combining space time trellis codes (STTC) with turbo codes. In LST, two codes that are inner and outer codes are concatenated in the serial fashion. The inner codes are turbo Pi codes suggested in DVB-RCS NG system, and outer codes are STTC codes proposed by Blum. The interleaver technique is used to efficiently combine two codes. And we proposed and simulated that a full iteration method between turbo decoder and BCJR decoder to improve the performance instead of only processing inner-iteration turbo decoder. The simulation results of proposed effective layered method show improving BER performance about $1.3 \sim 1.5 \mathrm{~dB}$ than conventional one.

Key words : MIMO, space time code, turbo code, interleaver

\section{1. 서 론}

차세대 무선 통신 시스템에서는 고품질, 다양한 서비스를 요구하고 있다. 따라서 높은 신뢰도와 함께 고속의 데이터 전 송이 필요하기 때문에 스펙트럼의 효율성을 높이면서 다이버 시티 및 부호화 이득을 향상시키기 위한 연구가 진행 중에 있 다. 이러한 요구를 만족시키기 위한 연구 방법은 높은 성능을 갖는 채널 부호화 기술이 있다. 또한 다수의 송수신 안테나를 이용한 시공간 부호화 기술 기반의 $\mathrm{MIMO}$ 시스템에서 다이버 시티 이득과 부호화 이득을 동시에 얻는 방법이 있다.

채널 부호화 기술은 최근 무선 통신 시스템에서 필수적으로 사용되어지고 있다. 이러한 채널 부호화 기술 중에 터보 부호 화기는 그 성능이 Shannon이 제시하는 이론적 한계 값에 매
우 근접하는 우수한 오류정정 능력을 보이고 있다.(Glavieux, and Berrou, 1996) 터보 부호화기는 1993년 Berrou에 의해 논 문발표 후 1-2년간에 걸쳐 터보 부호의 성능이 입증되었고, 현재는 각종 무선통신시스템에서 표준안으로 채택 되고 있다. 이러한 터보 부호는 높은 SNR에서는 오류 마루 현상이 존재 하기 때문에 새로운 터보 부호화 방식인 터보-Pi 부호화기를 이용하여 오류 마루 현상을 극복할 수 있다.

시공간 부호는 크게 전송 다이버시티와 부호화 이득을 동시 에 가지는 시공간 격자부호와 부호화 이득은 없고 전송 다이 버시티만 가지는 시공간 블록부호로 나눌 수 있다. 시공간 블 록부호는 부호화 이득은 없지만 최적의 다이버시티 이득과 함 께 간단하게 부복호기를 구성할 수가 있다. 하지만 고품질의 높은 신뢰도를 요구하는 무선 통신 시스템에서는 부호화 이득

† 교신저자 : 정회원, jwjung@hhu.ac.kr 010)9319-4425

* 정회원, bokddori@hhu.ac.kr 010)4763-8588 
을 가지는 시공간 격자부호화 기술이 더 적합하다. 시공간 격 자부호화 기술은 1998년 Tarokh에 의해 처음으로 발표되었 고, 그 이후 Baro, Blum 등에 의해 성능이 좋은 부호화 구조 가 연구되어졌다.(Calderbank et al., 1998)

최근에는 시공간 블록 부호화 기법과 반복 부호를 결합하는 계층적인 시공간 부호화 기법이 대두되고 있다.(Yeap et al., 2011) 그러나 높은 신뢰도를 요구하는 최근의 시스템에서는 코딩 이득을 가지지 않는 시공간 블록부호는 부호 성능면에서 효율성이 떨어져서 적합하지가 않다. 따라서 본 논문에서는 다이버시티 이득과 함께 부호화 이득을 동시에 가지는 Blum 에 의해 제안된 32-state의 시공간 격자 부호화 기법을 외부 부호로 하고, 터보 부호를 내부 부호로 구성하는 계층적 부호 화 방식을 제안하며, 이에 대한 성능을 기존의 방식과 분석하 였다. 두 시스템의 결합 시 터보 복호기의 입력 값으로는 시공 간 격자 복호기를 이용하여 연판정 된 비트를 입력 값으로 필 요로 한다. 따라서 시공간 격자 복호기로는 연판정 된 값을 출 력하는 $\mathrm{BCJR}$ 복호 기법을 이용하였다. 효율적으로 두 부호기 를 연접시키기 위하여 인터리버 기법을 사용한다. 시공간격자 부호와 반복부호를 연접하는 연구는 대부분 개별적으로 복호 하는 방식이 대부분이며, 본 논문에서는 신뢰도를 향상시키기 위하여 시공간 격자부호와 반복 부호를 연접하였다. 그리고 터보 부호 내부에서만 이루어지는 기존의 방법과는 다르게 시 공간 격자부호의 복호 방식을 연판정 출력을 위한 $\mathrm{BCJR}$ 알고 리즘을 적용하여 터보 복호와 함께 전체적인 반복을 하여 성 능이 향상되는 것을 시뮬레이션을 통하여 확인하였다. 시뮬레 이션 결과 본 논문에서 제시하는 효율적인 연접 방식을 이용 하면 일반적인 연접 방식에 비하여 약 $1.3 \sim 1.5 \mathrm{~dB}$ 의 성능이 향상됨을 알 수 있다.

\section{2. 터보 $\mathrm{Pi}$ 부호와 결합된 계층적 시공간 격자 부호}

최근의 통신 시스템에서 요구하는 사항들을 만족시키기 위 해서는 $\mathrm{N}$ 개의 송신 안테나와 $\mathrm{M}$ 개의 수신안테나를 이용하여 다이버시티 이득을 가지는 시공간 부호와 함께 강력한 오류 정정율을 보이는 채널 부호화 기법을 연접하여 전송하여야한 다. 이때 연접시키고자 하는 채널 부호화 기법과 함께 시공간 부호의 선택에 따라서 성능의 차이점을 보이게 된다. 따라서 본 논문에서는 채널 코딩 기법으로는 현재 다양한 통신 시스 템에서 사용되어지고 있고, 차세대 $\mathrm{DVB}-\mathrm{RCS}$ 시스템에서 표 준으로 채택되어져 사용되어지고 있는 터보 $\mathrm{Pi}$ 부호를 사용 한다. 또한 터보 $\mathrm{Pi}$ 부호와 연접 시키기 위한 시공간 부호화 기법으로는 $\mathrm{MIMO}$ 기술의 특성인 다이버시티 이득과 함께 부호화 이득을 동시에 가지는 시공간 격자 부호를 사용한 다.(Blum and Lin, 2000) 다음 그림 1은 이러한 터보 Pi 부호 와 함께 시공간 격자 부호를 연접시키는 기본적인 구조를 나 타낸다.

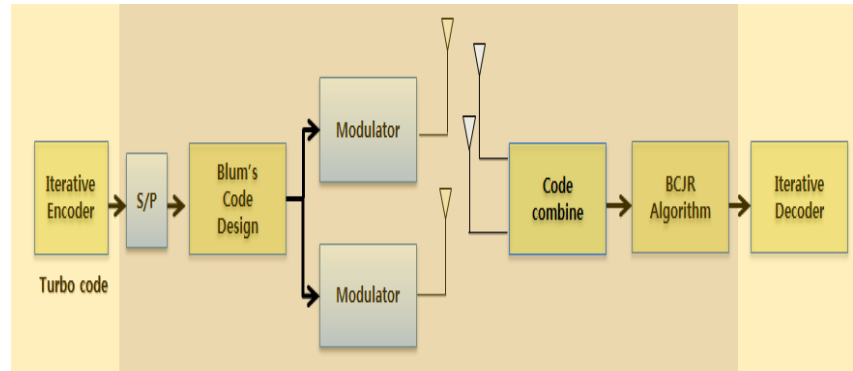

Fig. 1 STTC combined with turbo Pi code

전송하고자 하는 데이터는 먼저 채널 부호화 기법인 터보 $\mathrm{Pi}$ 부호화기를 통하여 부호화되어진다. 채널 부호화되어진 비 트는 $\mathrm{S} / \mathrm{P}($ Serial / Parallel) 를 통하여 시공간 격자부호화기와 결합되어져 송신하게 되는 구조이다. 레일레이 페이딩 채널을 통과한 수신신호 $r_{j, t}$ 는 $\mathrm{M}$ 개의 수신 안테나 수만큼 결합하여 평균값을 취하는 code combine 계산을 통하여 $\mathrm{MIMO}$ 의 특성 인 다이버시티 이득을 가지게 된다. Code combine 된 심볼은 시공간 격자 복호기로 입력된다. 일반적인 시공간 격자 복호 기에서 사용되어지는 비터비 복호기는 강판정 된 값을 출력하 기 때문에 연판정 된 입력 값을 필요로 하는 터보 $\mathrm{Pi}$ 복호기 에 사용할 수 없다. 따라서 연판정 된 출력 값을 가지는 $\mathrm{BCJR}$ 복호기를 사용하여야한다. 연판정 된 $\mathrm{BCJR}$ 복호기의 값이 터 보 $\mathrm{Pi}$ 복호기로 입력되어져 터보 $\mathrm{Pi}$ 복호기에서의 반복 복호 를 통하여 data를 복호하게 된다. 시공간 격자 부호와 함께 터 보 $\mathrm{Pi}$ 부호의 특성은 2-1, 2-2에서 설명한다.

\section{1 터보 $\mathrm{Pi}$ 부호}

$\mathrm{DVB}-\mathrm{RCS}$ 를 기반으로 하는 터보 부호는 기존의 $1 \mathrm{bit}$ 를 입 력하여 출력하는 binary 부호가 아니라 2 bit를 입력하고 출력 하는 이진 바이너리(double binary) 부호이다.(ETSI EN 301 790) 이진 바이너리 구조의 CRSC (Circular Recursive Systematic Convolutional)부호는 반복 복호 기법을 이용하여 Shannon이 제시하는 이론적 한계 값에 매우 근접하는 우수한 오류정정 능력을 보이고 있다. 하지만 높은 $\mathrm{SNR}$ 에서는 오류 마루 현상이 존재하여 이를 극복하기 위해 $\mathrm{DVB}-\mathrm{RCS} \mathrm{NG}$ 부 호화 방식인 터보 $\mathrm{Pi}$ 부복호기 구조를 사용하였다.(Douillard and Berrou, 2005) 이러한 터보 $\mathrm{Pi}$ 부호화기는 기존의 이중 바 이너리 구조를 이용하는 터보 구조와 동일하며, 단지 16 상태 를 이용하는 구조이다.

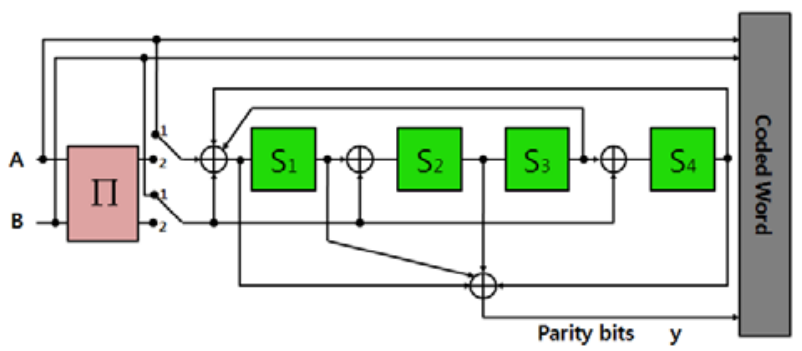

Fig. 2 Structure of turbo Pi encoder 
기존의 터보 부호화기는 3개의 $\mathrm{S} 1, \mathrm{~S} 2, \mathrm{~S} 3$ 메모리를 가지며 8-state로 구성되어 있다. 터보 Pi 부호화기는 4개의 메모리를 가지며 16 개의 state를 이용하여 각각의 상태가 가지는 해밍 거리차이를 더 크게 만들어 오류 마루 현상을 제거할 수 있는 구조이다. Double binary bit A, B의 2 bit가 입력되면, 그림 2 의 $\mathrm{RSC}$ 부호화기를 거쳐 출력된 bit의 $2 \mathrm{bit}$ 단위의 Permutation 을 하여 나온 2 bit를 다시 RSC부호화 하여 각 부호화율에 적합하게 펑처링 한다. Permutation은 수신단에서 버스트 에러를 방지하고 오류마루현상(error floor)를 방지하 기 위한 인터리버 효과를 나타낸다.

\section{2 시공간 격자 부호}

$\mathrm{MIMO}$ 시스템에서는 $\mathrm{N}$ 개의 송신 안테나와 $\mathrm{M}$ 개의 수신안 테나를 이용하여 통신을 한다. 그림 3는 $\mathrm{MIMO}$ 시스템에서의 Blum에 의해 제안된 32-state의 시공간 격자 부호화기 구조 이다.(Gans and Foschini, 1998)

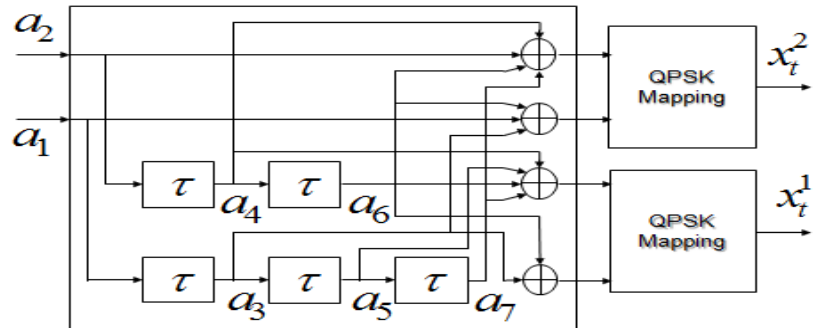

Fig. 3 Structure of STTC based on 32-state

$\mathrm{a}_{1}, \mathrm{a}_{2}$ 는 전송하고자 하는 $\mathrm{bit}$ 이고 $\mathrm{x}_{\mathrm{t}}{ }^{1}, \mathrm{x}_{\mathrm{t}}{ }^{2}$ 는 시공간 격자 부호 화 이후의 QPSK 변조 되어진 전송 심볼을 나타낸다. 채널 환 경은 심볼 주기 $\mathrm{T}$ 동안 서로 독립적인 분포를 가지는 레일레 이 페이딩 채널로써 주기 $\mathrm{T}$ 동안 채널의 변화가 없고, 수신단 에서는 채널 추정을 정확히 알고 있다고 가정하였다. 이때의 수신 신호 $r_{j, t}$ 는 다음과 같이 나타낼 수 있다.

$$
r_{j, t}=\sum_{i=1}^{N} h_{i, j} x_{t}^{i}+\eta_{t}
$$

여기서 $t(t=1,2, \cdots, T)$ 는 송신신호에 대한 시간이며, $x_{t}^{i}$ 는 시 간 $t$ 에서 $i(i=1,2, \cdots, N)$ 번째 송신안테나에서의 전송 심볼 이 다. 그리고 $h_{i, j}$ 는 $i$ 번째 송신안테나와 $j$ 번째 수신 안테나에서 의 페이딩 진폭을 나타내며, $\eta_{t}$ 는 가우시안 잡음을 나타낸다. 시공간 부호화되어 전송되어진 수신 신호 $r_{j, t}$ 는 수신 안테나 의 수에 따라 code combine을 통하여 신호를 합성하게 된다. 합성되어진 신호는 복호를 위하여 $\mathrm{BCJR}$ 복호기에 입력된다. $\mathrm{BCJR}$ 복호기에서는 branch matrix, forward state matrix, backward state matrix를 구하기 위하여 입력 값에 따른 출력 값과 함께 변화하는 state를 나타내는 격자도를 이용하여 복 호하게 된다.(Gimmler and Kienle, 2010)

\section{3. 터보 $\mathrm{Pi}$ 부호와 시공간 격자 부호의 효율적인 연접 방법}

통신 시스템에서 채널의 특성상 오류가 연속으로 발생하는 경우가 있다. 오류가 한곳에 집중적으로 발생할 경우 터보 $\mathrm{Pi}$ 부호기의 성능이 열화되어 오류 정정율이 감소하게 된다. 따 라서 터보 $\mathrm{Pi}$ 부호화 시공간 격자 부호를 효율적으로 연접하 는 방법이 연구되어져야한다. 본 논문에서는 오류가 집중되어 발생할 경우 오류를 분산시키는 기능을 하는 인터리버를 터보 $\mathrm{Pi}$ 부호와 시공간 격자 부호 사이에 첨가하여 그림 1 에서의 구조보다 효율적인 송신 구조를 제안한다. 또한 interleaver를 가지는 구조는 터보 부호의 오류마루 현상을 방지하는 효과도 가지고 있다.

차세대 무선통신에서 고품질, 고속전송을 만족시키기 위한 방안으로 레일레이 페이딩 채널에서 터보 $\mathrm{Pi}$ 부호와 시공간 격자부호를 효율적으로 결합시키기 위한 방안으로 다음 그림 4 와 같은 구조를 제안한다.

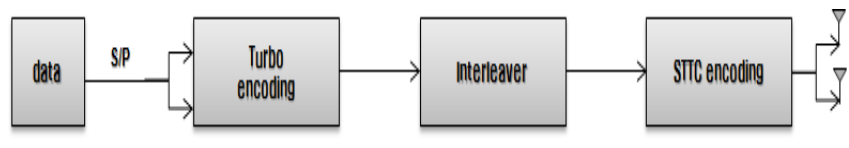

(a) Transmitter

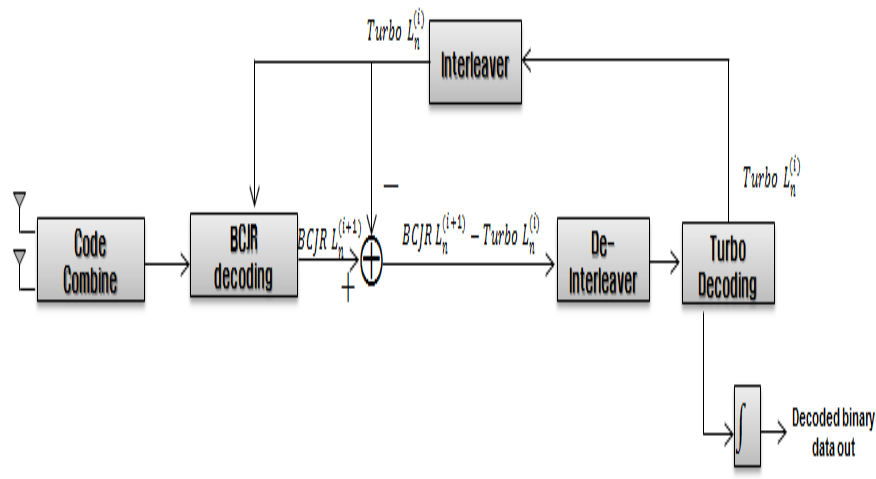

(b) Receiver

Fig. 4 Proposed STTC combined with turbo Pi code

송신 구조는 2장에서 제시된 구조에 인터리버를 접목시키는 구조이다. 터보 $\mathrm{Pi}$ 부호화를 거친 비트 스트림은 인터리버 후 에 시공간 격자 부호에 입력되게 되는 구조이다.

송신된 신호는 레일레이 페이딩 채널을 통과하여 수신되어 진다. 수신 신호는 code combine을 통하여 합성된 신호가 $\mathrm{BCJR}$ 복호기로 입력되어진다. 시공간 격자 복호단에서 $\mathrm{BCJR}$ 복호기를 통하여 수신 비트 스트림 크기만큼의 LLR 값이 출력된다. $\mathrm{BCJR}$ 의 복호 방식은 터보 $\mathrm{Pi}$ 부호의 복호 방식과 동일하며, 각 상태에서 ' 0 '의 확률과 ' 1 '의 확률을 계 산하여 순방향 메트릭, 역방향 메트릭을 계산하여 최종적으 로 $L L R=\log \frac{P(x=+1)}{P(x=-1)}$ 값을 계산한다. 추정되어진 LLR 값 
은 역-인터리버를 통하여 송신단에서의 인터리버 이전의 주 소로 재배치하여 터보 $\mathrm{Pi}$ 복호기에 입력된다. 일반적인 터보 $\mathrm{Pi}$ 복호기는 복호기 내부 반복을 통하여 성능을 향상시키는 구조이지만, 본 논문에서 제안하는 복호기 구조는 터보 $\mathrm{Pi}$ 복 호기에서 계산되어 추정된 LLR 값을 다시 인터리버를 통하여 $\mathrm{BCJR}$ 복호기에 업데이트 시켜주는 방식이다. $\mathrm{BCJR}$ 복호기에 업데이트 되어진 LLR값을 이용하여 $\mathrm{BCJR}$ 복호기에서는 새 로이 추정된 $\mathrm{BCJR} \mathrm{LLR}$ 값을 계산하게 된다. 추정된 $\mathrm{BCJR}$ LLR값은 이전에 터보 복호기의 LLR 값과의 차를 구하여 역인터리버 후에 터보 복호기에 새로이 입력되게 된다. 따라서 전체 반복을 통하여 터보 $\mathrm{Pi}$ 복호기와 $\mathrm{BCJR}$ 복호기가 함께 업데이트 되므로 터보 $\mathrm{Pi}$ 복호기 내부에서만 반복을 하였을 때보다 부호화 이득이 향상된다.

\section{4. 시뮬레이션 결과}

그림 5는 2 개의 송신안테나를 이용하는 32-state 구조를 가 지는 시공간 격자 부호화기를 이용하였을 때의 수신 안테나의 수에 따른 $\mathrm{BER}$ 성능과 함께 터보 $\mathrm{Pi}$ 와 시공간 격자 부호를 결합하였을 때의 시뮬레이션 결과를 나타낸다. 시뮬레이션에 서 사용한 터보 $\mathrm{Pi}$ 부호화기는 전송 bit의 크기 $\mathrm{K}=984$, 부호화 율 $\mathrm{R}=1 / 3$ 을 사용하였다. 시뮬레이션 환경은 심볼 주기 $\mathrm{T}$ 동 안 서로 독립적인 분포를 가지는 레일레이 페이딩 채널로써 주기 $\mathrm{T}$ 동안 채널의 변화가 없고, 수신단에서는 채널 추정을 정확히 알고 있다고 가정하였다. 변조방식은 QPSK 변조방식 을 적용하였다.

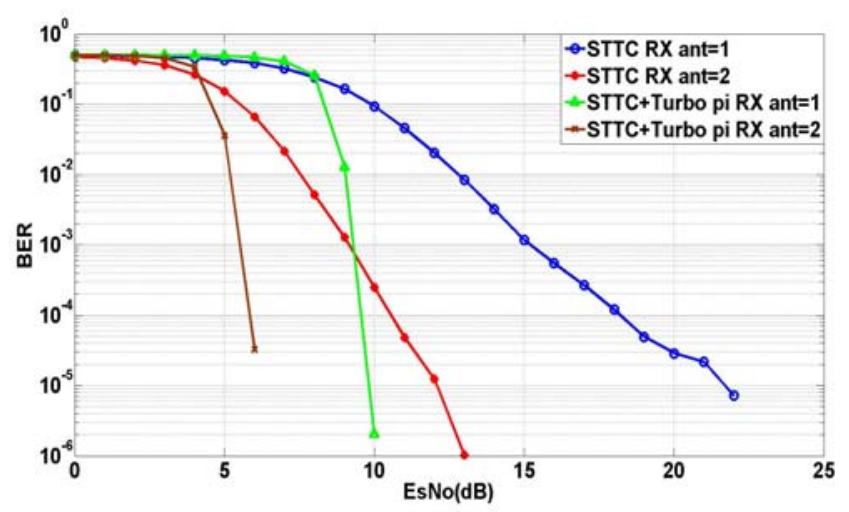

Fig. 5 BER performance of STTC

시공간 격자 부호만을 이용하였을 때의 시뮬레이션 결과는 $\operatorname{BER} 10^{-4}$ 에서 수신 안테나의 수가 1 개일 때 보다 2개일 때 약 $8 \mathrm{~dB}$ 의 성능이 향상됨을 알 수가 있다. 이러한 성능의 향상은 수신 안테나 수의 증가로 인한 다이버시티 이득으로 $3 \mathrm{~dB}$ 의 성능이 향상되었고, 시공간 격자 부호화 이득으로 인하여 약 $5 \mathrm{~dB}$ 의 성능이 향상됨을 알 수 있다.

시공간 부호와 터보 $\mathrm{Pi}$ 부호를 연접하였을 때의 시뮬레이션 결과는 2 개의 수신안테나일 때 1 개일 때 보다 약 $4 \mathrm{~dB}$ 의 성능
이 향상된다. 또한 시공간 격자 부호만을 이용하였을 때의 $\mathrm{BER}$ 성능과 비교를 통하여 터보 $\mathrm{Pi}$ 채널 부호화 이득을 가지 는 것을 알 수 있다. 수신 안테나의 수가 1 개일 때는 약 $8.5 \mathrm{~dB}, 2$ 개일 때는 약 $5 \mathrm{~dB}$ 의 성능이 향상되었다. 터보 $\mathrm{Pi}$ 부호 와 시공간 격자 부호를 결합하였을 때 채널부호의 이득과 함 께 시공간 격자 부호의 부호화 이득, 다이버시티 이득으로 인 하여 성능이 향상됨을 알 수 있다.

그림 6은 3장의 효율적인 터보 $\mathrm{Pi}$ 부호와 시공간 격자 부호 의 연접 구조에서 인터리버를 사용하고 제안하는 전체 반복을 통한 복호방법에서의 성능을 나타낸다. 시률레이션에서 사용 되어진 인터리버는 일반적으로 많이 사용되는 랜덤 인터리버 를 사용하였다.

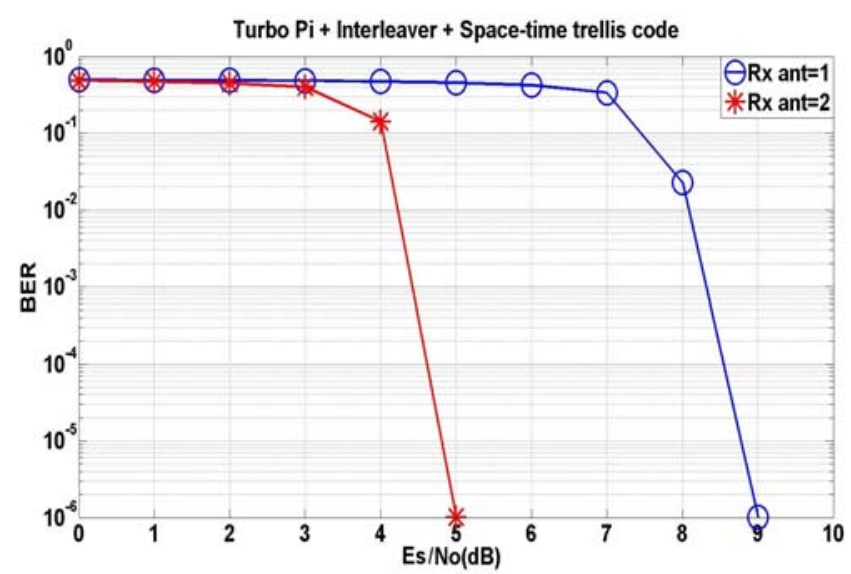

Fig. 6 BER performance of proposed STTC combined with turbo Pi code

다른 시뮬레이션의 결과와 동일하게 안테나의 수가 증가함 에 따라 다이버시티 이득과 함께 시공간 격자 부호의 부호화 이득으로 인하여 수신안테나의 수가 2 개일 때 1 개일 때 보다 $\mathrm{BER} 10^{-4}$ 에서 약 $4 \mathrm{~dB}$ 의 성능이 향상됨을 알 수 있다. 그림 5 의 시률레이션 결과와 비교하였을 때, 인터리버 효과와 함께 전체 반복을 통하여 약 $1.5 \mathrm{~dB}$ 의 성능이 향상됨을 알수가 있 다. 따라서 본 논문에서 제안하는 효율적인 연접 방법과 함께 전체 반복을 통한 복호 방법은 높은 신뢰도를 요구하는 최근 의 무선통신 시스템에서 적합한 것으로 사료된다.

\section{5. 결 론}

최근의 무선 통신시스템에서는 양질의 데이터 전송과 함께 빠른 전송을 요구하고 있다. 따라서 본 논문에서는 다이버시 티 이득과 함께 부호화 이득을 동시에 가지는 시공간 격자 부 호를 이용하였다. 또한 채널 부호화 기술로써 현재 여러 시스 템에서 많이 사용되고 있는 반복 복호를 이용하는 터보 $\mathrm{Pi}$ 부 호를 연접시키는 방안을 제시하고 효율적으로 연접시키기 위 하여 인터리버의 사용과 함께 수신단에서의 반복복호 방법을 기존과는 다르게 전체 반복 복호하는 방법을 제시하고 시뮬레 이션을 통하여 성능을 검증하였다. 
2 개의 수신 안테나에서의 시뮬레이션 결과를 BER $10^{-4}$ 을 기준으로 각각 비교하면, 시공간 격자 부호에서는 $\mathrm{Es} / \mathrm{No}$ 가 약 $11 \mathrm{~dB}$ 일 때 만족하며, 터보 $\mathrm{Pi}$ 부호와 시공간 격자 부호를 연접 하였을 때는 약 $5.8 \mathrm{~dB}$ 에서 성능이 검정되었다. 최종적으로 제 안한 구조에서는 $\mathrm{Es} / \mathrm{No}$ 가 약 $4.5 \mathrm{~dB}$ 에서 성능이 만족함을 알 수 있다. 따라서 제안한 구조를 사용하였을 때 일반적인 터보 $\mathrm{Pi}$ 와 시공간 격자 부호를 결합한 구조보다 수신 안테나의 수 에 따라 약 $1.3 \mathrm{~dB}^{\sim} 1.5 \mathrm{~dB}$ 의 성능이 향상되므로 본 논문에서 제 시한 구조가 최근의 무선통신 시스템에 적합하다고 사료된다.

\section{후 기}

본 연구는 지식경제부 및 정보통신산업진흥원의 대학 IT연 구센터 지원사업의 연구결과(NIPA-2012-H0301-12-2005)와 방위사업청과 국방과학연구소의 지원(계약번호 UD110101DD) 으로 수행되었습니다.

\section{참 고 문 헌}

[1] Blum, R. S. and Lin, X.(2000), "Improved space-time codes using serial concatenation", IEEE Commun. Lett. Vol. 4, pp. 221-223.

[2] Calderbank, A. R., Seshadri, N., and Tarokh, V.(1998), "Space-time codes for high data rate wiress communication: performance criterion and code construction", IEEE Trans. Inform. Theory, pp. 744-765.

[3] Douillard, C. and Berrou, C.(2005), "Turbo Codes with Rate $-\mathrm{m} /(\mathrm{m}+1)$ Constituent Convolutional Codes", IEEE Trans. Commun., Vol. 53, No. 10, pp. 1630-1638.

[4] Gans, M. J. and Foschini, G. J.(1998), "On limits of wireless communication in a fading environment when wsing multiple antennas", Wireless Personal Communication, Vol. 5, No. 3, pp. 311-335.

[5] Gimmler, C. and Kienle, F.(2010), "Space-time bit trellis codes”, 2010 International ITG Conference, pp. 18-21.

[6] Glavieux, A. and Berrou, C(1996), "Near optimum error correcting coding and decoding: turbo codes", IEEE Trans. Commun., Vol. 44, No. 10, pp. 1261-1271.

[7] Yeap, B. L., Hanzo, L., Tee, R. Y. S., Ng, S. X., and Liew T. H.(2011), "Turbo Coding, Turbo Equalisation and Space-Time Coding: EXIT-Chart-Aided NearCapacity Designs for Wireless Channels"

[8] "Interaction Channel for Satellite Distribution Systems", DVB, ETSI EN 301 790, Vol. 1. 2. 2. 